\title{
Students' Mindsets for Learning and Their Neural Underpinnings
}

\author{
Kirsi Tirri' ${ }^{1}$ Teija Kujala ${ }^{2}$ \\ ${ }^{1}$ Department of Teacher Education, University of Helsinki, Helsinki, Finland \\ ${ }^{2}$ Cognitive Brain Research Unit, Institute of Behavioural Sciences, University of Helsinki, Helsinki, Finland \\ Email: Kirsi.Tirri@helsinki.fi, Teija.M.Kujala@helsinki.fi
}

Received 3 June 2016; accepted 16 August 2016; published 19 August 2016

Copyright (C) 2016 by authors and Scientific Research Publishing Inc.

This work is licensed under the Creative Commons Attribution International License (CC BY). http://creativecommons.org/licenses/by/4.0/ (c) (i) Open Access

\begin{abstract}
It has been shown that individuals with a growth mindset for learning see mistakes as opportunities to learn and improve, whereas for fixed-minded individuals mistakes indicate lack of ability. Earlier empirical research on mindsets includes both quantitative surveys and qualitative approaches with observations and stimulated recall method. During performance monitoring it is possible to probe event-related brain potentials (ERPs), enabling the investigation of the neural basis of students' different reactions to mistakes. ERP studies have shown that growth mindset is associated with an enhancement of the error positivity (Pe), an ERP reflecting awareness of and attention allocation to mistakes. More growth-minded individuals also show superior accuracy after mistakes compared to those endorsing more of a fixed mindset. Most importantly, Pe amplitude mediates the relationship between mindset and post-error accuracy. These results suggest that neural activity indexing online awareness of and attention to mistakes is intimately involved in growth-minded individuals' ability to rebound from mistakes. In this article we review and connect educational, psychological and neuroscientific points of view to investigate the role of mindsets related to learning.
\end{abstract}

\section{Keywords}

Mindset Orientation, Learning, Mistakes, Performance Monitoring, Event-Related Potentials

\section{Introduction}

Students' implicit beliefs about the nature of their intelligence ("mindsets”) are an important factor in predicting school motivation and performance in all school subjects. Carol Dweck's (2006) theory of mindsets builds on positive psychology approach to the malleable nature of human intelligence, which is in line with neuroscientific 
findings on the adaptive brain (e.g., Kujala \& Näätänen, 2010). According to Dweck’s (2006) definition, mindsets are beliefs that individuals hold about their most basic qualities and abilities. People with a growth mindset believe that intelligence, personality, and abilities can be developed, whereas people with fixed mindsets believe that basic qualities, such as intelligence, are static and unalterable.

Students with an "entity" mindset believe that their intelligence is fixed and cannot be improved much by effort, whereas students with an "incremental" mindset believe that they can increase their abilities by working harder (Blackwell, Trzesniewski, \& Dweck, 2007). Students' mindsets shape their responses to academic challenge, independent of their actual intellectual ability. Students holding entity beliefs show poorer self-efficacy, give up more easily and adopt maladaptive strategies, which are reflected also in neural responses, to cope with failure and negative feedback (Yeager \& Dweck, 2012). These maladaptive responses are especially obstructive as innovative and creative thinking with risk-taking and flexibility are increasingly essential learning skills in the 21st century (Dweck, 2009). Research has shown that students' mindsets play a vital role in their learning success and in confronting educational challenges. Mangels et al. (2006) found that students who viewed intelligence with a fixed-mind emphasized performance goals ("looking smart"), whereas students with a growth mindset emphasized learning goals ("becoming smart"). A fixed mindset leaves students vulnerable to negative feedback and can lead to avoidance of challenging learning opportunities, whereas a growth mindset helps students to handle failure (Mangels, Butterfiels, Lamb, Good, \& Dweck, 2006).

Female students that hold entity theories of their intelligence are also more likely to be affected by these stereotypical beliefs and this subsequently leads to declines in female performance in Science, Technology, Engineering and Mathematics (STEM) related subjects and skills (Good, Aronson, \& Harder, 2008; Tirri \& Nokelainen, 2010). Similarly, it has been found that students with a growth mindset have higher achievement during challenging school transitions, and their completion rates in demanding school courses are higher (Blackwell, Trzesniewski, \& Dweck, 2007; Yeager \& Dweck, 2012). Furthermore, the growth mindset, whether innate or taught, seems to lower adolescents' aggression and stress levels and enhances their school performance (Yeager, Trzesniewski, \& Dweck, 2012; Yeager, Trzesniewski, Tirri, Nokelainen, \& Dweck, 2011). Stimulating an incremental mindset to improve adaptive learning behavior and motivation is therefore of great importance in advancing students' learning, and requires more insight into how the neural and cognitive effects of mindsets are linked to school-related behavior, such as performance and educational choices made.

The aim of this paper is to provide a review on the role of mindsets in students' learning as well as present evidence on neural processes underlying different mindsets. We will present both quantitative and qualitative studies on these themes and intervention studies that have been successful in changing mindset orientations of students. Moreover, we will discuss how brain research can add value to these studies by providing objective evidence on the neural processes associated with different mindsets and their changes after intervention. Neuroscientific studies have shown that certain areas of the brain respond powerfully when people observe or engage in intentional activities (Iacoboni, Molnar-Szakacs, Gallese, Buccino, Mazziotta, \& Rizzolatti, 2005). In an educational context, this means that teachers should strive to learn about the mindsets and cultures of their students in relation to the school and the relevant subject matter and make educational goals as explicit as possible to the students. Social and affective neuroscience informs teachers and parents why and how students learn, which in turn may lead to innovative, effective methods for engaging students in meaningful learning (Immordino-Yang, 2009). The influence of students' mindsets to learning in diverse contexts and grade-levels provides important knowledge to teachers and educationalist in designing optimal learning environments. In this paper we review current research on this topic with the aim to connect educational, psychological and neuroscientific points of view to investigate the role of mindsets related to learning.

\section{Educational Interventions on Mindsets}

According to previous research, mindsets are quite stable, yet they are alterable through educational interventions (Aronson, Fried, \& Good, 2002; Blackwell, Trzesniewski, \& Dweck, 2007; Dweck, 2012; Yeager, Trzesniewski, Tirri, Nokelainen, \& Dweck, 2011; Yeager \& Dweck, 2012). The main feature of such interventions has been to teach students about the neuroplasticity of the brain and its potential to change and reorganize when people learn and practice new ways of thinking (Aronson, Fried, \& Good, 2002; Blackwell, Trzesniewski, \& Dweck, 2007; Yeager \& Dweck, 2012). Even the effects of brief interventions have proven to be powerful and relatively long lasting (Paunesku, 2013; Rattan, Good, \& Dweck, 2012). For example, students' incremental 
theory of intelligence was successfully encouraged in an intervention that emphasized the importance of effort, strategies, and help from others in learning (Yeager \& Dweck, 2012). Mindsets can be induced simply after reading a scientific article that describes intelligence as being immutable and stable (fixed mindset induction) or as being a malleable characteristic that is developed through learning and effort (growth mindset induction) (Chiu, Hong, \& Dweck, 1997; Hong, Chiu, Dweck, Lin, \& Wan, 1999). Studies such as these indicate that even slight mindset messages can have noticeable effects on attitudes and motivation, which may transfer to longer term learning outcomes like GPA (e.g., Yeager \& Walton, 2011).

In a study by van Atteveldt, Fernandez, de Vries Lentsch, \& Krabbendam (2015), the overall aim was to investigate how 15-year old high school students' $(\mathrm{N}=60)$ mindsets about mathematical ability influence their responses to making mistakes and receiving negative feedback while solving mathematical equations. Moreover, as previous research has shown that a student's mindset can be altered by information about brain plasticity (Blackwell, Trzesniewski, \& Dweck, 2007), the study assessed whether these failure-related responses can be influenced with a mindset induction prime prior to the math task. In this study a mathematical set-shifting task was used. Set-shifting requires flexible switching to changing rules. The researchers predicted that students with an entity mindset would have more difficulty with the challenging nature of the task and the requirement to change strategies. This was based on findings that entity beliefs often result in strategy perseverance and effort withdrawal, whereas an incremental mindset more often results in strategy change and increased effort (Robins \& Pals, 2002).

To induce an entity or an incremental mindset, researchers used a short PowerPoint presentation with two versions that were of equal length, had an equal amount of text on each slide and contained identical pictures. In the Entity version, the message was that each brain is unique and that how good you are at math depends on how your brain has been shaped. In the Incremental version, the message was that you can change the connections in your brain with effort, and that how good you are at math therefore depends on how much you practice.

The students from entity group demonstrated significantly more post-error slowing than the students from incremental group. A significant interaction of school level and priming condition was also found, there being stronger priming effects for the lower school level. These results suggest that a fixed mindset obstructs students from learning from mistakes and feedback, adding important knowledge on mindset by showing that school level, trait mindset, and induced mindset all contribute to dealing with making mistakes. The results of this study have important educational implications for teachers and schools, since the participants were school-aged students and the tasks used were school-related tasks. These results can therefore inform teachers to increase awareness of the importance of mindsets for math learning, and for motivation to persevere during challenging math assignments.

\section{Brain Research on Students' Mindsets}

Brain research on mindsets has used performance monitoring and event-related brain potentials (ERPs) for investigating the neural basis of students' different reactions to mistakes. By combining the assessment of behavioral responses and recordings of ERPs, one can pinpoint the distinct stages during error perception and detection and the subsequent actions. ERPs reflect these processes in the temporal accuracy of millisecond's scale (Luck, 2005). The error related negativity (ERN) and error positivity (Pe) are two widely studied ERPs elicited during error processing that relate to adaptive behavioral adjustments following mistakes. ERN reaches its peak 50 - 100 ms after an error in a simple reaction time task (Falkenstein, Hohnsbein, Hoormann, \& Blanke, 1991) and is thought to be originated in anterior cingulate cortex (ACC; Gehring, Liu, Orr, \& Carp, 2012). It has been suggested that ERN is the earliest response reflecting error detection (Bartholow, Pearson, Dickter, Sher, Fabiani, \& Gratton, 2005). ERN is followed by error positivity (Pe), peaking at $200-600 \mathrm{~ms}$ after the response (Overbeek, Nieuwenhuis, \& Ridderinkhof, 2005). Several brain regions, including ACC, were suggested to contribute to Pe generation (Herrmann, Römmler, Ehlis, Heidrich, \& Fallgatter, 2004). Pe is thought to reflect a conscious registration of an error, which is followed by a binary (correct vs. error) assessment of the response. It has been suggested that Pe might be associated with conscious awareness of an error (Endrass, Franke, \& Kathmann, 2005; Klein, Ullsperger, \& Danielmeier, 2013; Murphy, Robertson, Allen, Hester, \& O’Connell, 2012; Nieuwenhuis, Ridderinkhof, Blom, Band, \& Kok, 2001), the accumulation of evidence on the occurrence of an error (Steinhauser \& Yeung, 2010), and motivated attention allocation to the error (Ridderinkhof, Ramautar, \& Wijnen, 2009). P3, in turn, is elicited by target stimuli in attended inputs at 200 - 600 ms after target onset 
(Donchin \& Coles, 1988). It is thought to reflect perceptual, attentional, and memory-updating processes.

To our knowledge, there are so far only few studies which have utilized ERPs in investigating mindsets. The results obtained are very promising, suggesting that ERPs bring new insight to the mechanisms underlying mindsets and their malleability. Mangels, Butterfield, Lamb, Good, and Dweck (2006) measured ERPs in college students endorsing a fixed or growth mindset while they performed a difficult general knowledge test. They found that compared to individuals with a fixed mindset, individuals with a growth mindset were better in remediating errors irrespective of confidence when the mistake was initially made. These two student groups also oriented to some extent differently to information relevant for performance. This was indicated by a larger P3 response in participants with a fixed mindset compared to growth mindset to both unexpected and expected negative performance-relevant feedback. Although Mangels et al. (2006) showed differences between mindsets in neural and behavioral responses to corrective information, their effects were elicited by feedback stimuli in a task in which performance accuracy was below chance and ambiguous until the presentation of feedback. Thus, their findings do not reflect the online influence of mindset on immediate reactions to errors.

Moser et al. (2011), in turn, aimed to extend these findings to undergraduate students by examining responselocked ERPs that tap into online internal performance monitoring processes elicited automatically by response execution in a speeded reaction time (RT) task. Specifically, the study examined ERN and Pe, in order to directly assess the effect of mindset on online performance monitoring and immediate self-initiated reactions to mistakes. In their study, the ERN, Pe, and behavioral adjustments following mistakes-post-error slowing (PES) and accuracy (PEA)-were measured in a simple two-choice RT task. Based on the links between a growth mindset, enhanced attention to corrective information, and adaptive reactions to mistakes, they predicted that growth mindset would be associated with a larger Pe amplitude and greater post-error adjustments. Because the ERN is less related to error processing per se and post-error behavioral adjustments, they further hypothesized that ERN would not be related to mindset. Finally, they examined whether the Pe mediated the relationship between mindset and post-error behavioral adjustments.

Their results showed that growth mindset was associated with an enhanced Pe amplitude reflecting the detection and conscious attention allocation to mistakes and with improved performance subsequently following the mistakes made. That the Pe mediated the relationship between mindset and post-error performance further underscores its significance in linking mindset to rebounding from mistakes. The study confirmed that enhanced Pe and post-error performance in individuals with a growth mindset is consistent with Mangels et al. (2006) study showing that growth mindset was associated with enhanced attention to corrective feedback following errors and subsequent error correction (Mangels, Butterfiels, Lamb, Good, \& Dweck, 2006). Moser et al. (2011) findings extend this prior work by showing that growth mindset is associated with heightened online awareness of and attention to errors as early as $200 \mathrm{~ms}$ following error commission. Whereas Mangels et al. (Mangels, Butterfiels, Lamb, Good, \& Dweck, 2006) measured responses to feedback stimuli in a task in which accuracy was ambiguous prior to the presentation of external feedback, Moser et al. (2011) found effects of mindset on internal error monitoring and immediate self-generated adjustments following mistakes. The finding that mindset was associated with Pe, and not ERN, is consistent with Moser et al. (2011) prediction and suggests that growth mindset is specifically associated with enhanced ACC-mediated error processing per se and not response selection or conflict (Steinhauser \& Yeung, 2010). Together with previous findings (Frank, D'Lauro, \& Curran, 2007; Hajcak, McDonald, \& Simons, 2003; Nieuwenhuis, Ridderinkhof, Blom, Band, \& Kok, 2001) their results suggest that one reason why a growth mindset leads to a greater likelihood of learning from mistakes is enhanced online error awareness (see Figure 1).

Overall, Moser et al. (2011) findings shed new light on the neural underpinnings of growth mindsets and their links of adaptive responses to mistakes and have important implications for academic and occupational performance. According to Moser et al. (2011) one concrete implication is that Pe amplitude and post-error adjustments measured in a simple reaction time task could serve as indicators of the effectiveness of programs that train growth mindsets towards learning. Such programs have been found to improve academic performance (Aronson, Fried, \& Good, 2002; Blackwell, Trzesniewski, \& Dweck, 2007). Implementing the procedure described in their paper could be an efficient way to provide objective evidence on the success of programs that have the potential to produce more highly motivated students and workers.

Whereas these two ERP studies presented above suggested that individual differences in mindsets relate to error-and feedback-related processes, the study by Schroder, Moran, Donnellan, \& Moser (2014), among undergraduate students $(\mathrm{N}=60)$ explored how experimentally induced mindsets are related to these neural processes. 


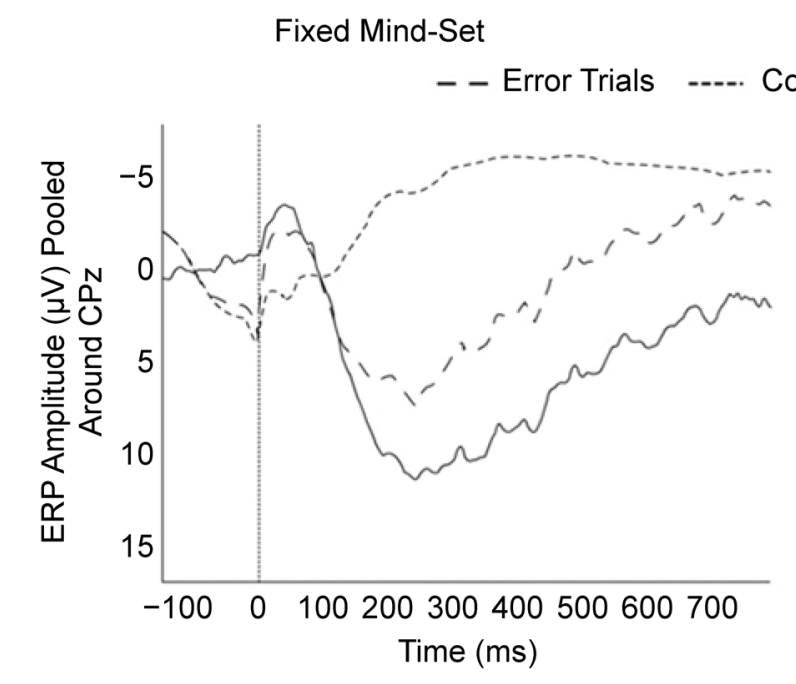

Growth Mind-Set Difference
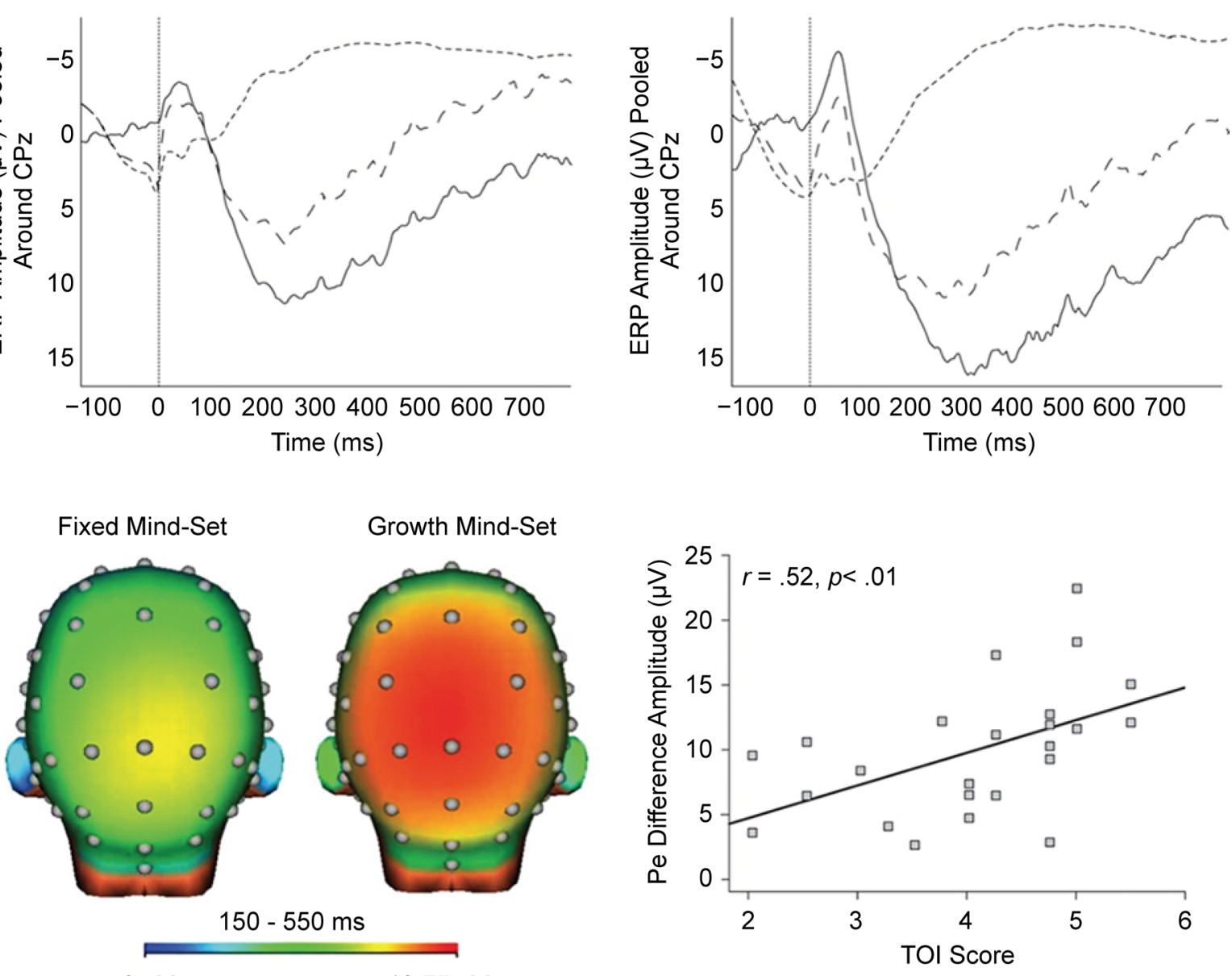

$$
0 \mu \mathrm{V} \quad 13.75 \mu \mathrm{V}
$$

Figure 1. The relationship between mindset and Error Positivity (Pe). Top: Response-locked grand-mean ERPs at centroparietal scalp for participants with fixed (left) and growth (right) mindsets (bottom vs. top Theory of Intelligence (TOI) scores). The response onset is at 0 . Mean split procedure for forming the groups was used for illustrative purposes. Left panel, bottom, shows voltage maps for the Pe (difference amplitude; responses for error trials minus those for correct trial counterparts) for the two mindsets. Right panel, bottom, a scatter plot of TOI score (self-reported) and Pe difference amplitude (at centroparietal scalp). Higher TOI scores reflect a higher endorsement of growth mindset. Figure adopted from Moser et al. (2011).

In that experiment the participants read a scientific article describing either that intelligence was malleable and able to change (growth mindset condition) or fixed and immutable (fixed mindset condition), a manipulation that has proven to induce mindsets (Yeager, Trzesniewski, Tirri, Nokelainen, \& Dweck, 2011) before they completed the same task as Moser et al. (2011). The study evaluated how the induction influenced both stimulus-locked and response-locked functions as well as indices of behavioral adjustment following errors, such as PES (Rabbitt, 1966), PEA (Laming, 1979) and post-error reduction of interference (PERI; Ridderinkhof, 2002).

First, the researchers predicted that individuals exposed to the fixed mindset would demonstrate reduced P3 and Pe, given the previous findings of reduced sustained attention to motivationally relevant information (Chiu, Hong, \& Dweck, 1997; Dweck, Chiu, \& Hong, 1995; Hong, Chiu, Dweck, Lin, \& Wan, 1999; Mangels, Butterfiels, Lamb, Good, \& Dweck, 2006; Moser, Schroder, Heeter, Moran, \& Lee, 2011). Second, because attention allocation in the previous mindset-ERP studies related to poorer post-error performance, they predicted that the individuals in the fixed condition would also show attenuated post-error behavioral adjustments (less PES, lower PEA, less PERI). They also expected no apparent effect on the amplitude of the ERN, given that they found no relation between the ERN and mindset endorsement in their previous study (Moser, Schroder, Heeter, Moran, \& 
Lee, 2011) and because mindset theory dictates differences in the subsequent evaluation of response outcomes (akin to the Pe), and not the initial detection of the response (ERN; Mangels, Butterfiels, Lamb, Good, \& Dweck, 2006).

The results of Schroder et al. (2014) showed that the P3 amplitude was enhanced and the Pe amplitude diminished in the Growth than Fixed condition. The results were interpreted so that the induction of growth mindset leads to prioritization of stimulus processing over response processing, whereas the opposite would be true for the fixed mindset. This is consistent with previous observations suggesting that those exposed to fixed mindset have enhanced concerns on achievement outcomes than mastering tasks (e.g., Chiu, Hong, \& Dweck, 1997). Crucially, it was found that the enhanced attention to responses, as reflected by the augmented Pe in the Fixed condition did not confer a behavioral advantage on subsequent trials. That is, there was no brain-behavior correlations in the Fixed mindset-condition. In contrast, early Pe amplitudes in the Growth condition were associated with faster and more accurate responding after errors (reduced PES and enhanced PEA). Although PES has been considered to be an adaptive response to errors, recent work suggests that its utility is dependent upon the task and context and it is not always positively related to PEA. In this sample, PES may have reflected off-task orienting processing because it was negatively related to PEA. Thus, the brain-behavior relationship patterns suggest that early attention allocation to errors was directly associated with efficient post-error behavior in the Growth condition only.

\section{Discussion}

Based on our review, it is evident that students' mindsets are associated with their academic achievement and, crucially, they can be influenced by appropriate interventions. In order to understand better the processes underlying the distinct mindsets and their plasticity, combined measures of task performance and concurrent ERP registrations have already proven very useful, even though such studies are still very scarce.

The results suggesting that mindsets are adaptive and can be influenced by interventions are very promising in the context of education. The studies have shown that even very brief intervention including knowledge on the value of effort and the potential for brains to adapt to new information has had a positive influence on students' learning and achievement. These kinds of interventions have a great potential to support learning in both teacher education and in schools. Brief interventions related to different subjects in schools could be performed in every grade-level, which could result in improved academic achievement of students.

ERP studies, providing the opportunity to inspect neural processes associated with perception, cognition, and responses have shown differences in the neural reactivity to mistakes in individuals with growth vs. fixed mindset. It was found that growth mindset is associated with an enhancement of the Pe (Moser, Schroder, Heeter, Moran, \& Lee, 2011; Schroder, Moran, Donnellan, \& Moser, 2014), an ERP reflecting awareness of and attention allocation to mistakes (Endrass, Franke, \& Kathmann, 2005; Klein, Ullsperger, \& Danielmeier, 2013; Murphy, Robertson, Allen, Hester, \& O’Connell, 2012; Nieuwenhuis, Ridderinkhof, Blom, Band, \& Kok, 2001). More growth-minded individuals have shown superior accuracy after mistakes compared to those endorsing more of a fixed mindset. Most importantly, Pe amplitude was found to mediate the relationship between mindset and post-error accuracy. These results suggest that neural activity indexing online awareness of and attention to mistakes is intimately involved in growth-minded individuals' ability to rebound from mistakes. Based on these results it is evident that some of the ERP components, such as Pe, could serve as indicators of neural changes following mindset induction. Linking interventions on mindset education with brain research would result in objective and measurable evidence on the effects of interventions on students' performance and achievement.

So far, the earlier research on mindsets has focused on adults or teenagers with short-term interventions. We still lack mindset research among children and with longitudinal effects on learning. It would be important to illuminate how younger students in schools change their fixed mindset in learning to a growth mindset and the long-term effects should be identified in their learning outcomes in school. A demonstration of intervention-induced positive influences on mindsets in young students would promote the large-scale application of such interventions early at school, which might improve the students' learning results early on. Consequently, the future work should attempt to establish evidence for the significant changes both in young students' still developing brains and in their learning outcomes at school. We argue that the mindsets of students, teachers, and parents play key roles in identifying and actualizing students' future potential. In future studies, we need a multidisciplinary approach to mindset education with an early start in the elementary school to promote learning re- 
silience of the students and build growth mindsets. In this attempt we need to utilize educational and psychological research along with brain activity studies in order to acquire quantitative and qualitative evidence with neural plastic changes.

\section{Acknowledgements}

This work was supported by Jane and Aatos Erkko Foundation and CICERO Learning Network, University of Helsinki.

\section{References}

Aronson, J., Fried, C. B., \& Good, C. (2002). Reducing the Effects of Stereotype Threat on African American College Students by Shaping Theories of Intelligence. Journal of Experimental Social Psychology, 38, 113-125. http://dx.doi.org/10.1006/jesp.2001.1491

Bartholow, B. D., Pearson, M. A., Dickter, C. L., Sher, K. J., Fabiani, M., \& Gratton, G. (2005). Strategic Control and Medial Frontal Negativity: Beyond Errors and Response Conflict. Psychophysiology, 42, 33-42. http://dx.doi.org/10.1111/j.1469-8986.2005.00258.x

Blackwell, L. S., Trzesniewski, K. H., \& Dweck, C. S. (2007). Implicit Theories of Intelligence Predict Achievement Across an Adolescent Transition: A Longitudinal Study and an Intervention. Child Development, 78, 246-263. http://dx.doi.org/10.1111/j.1467-8624.2007.00995.x

Chiu, C., Hong, Y., \& Dweck, C. S. (1997). Lay Dispositionism and Implicit Theories of Personality. Journal of Personality and Social Psychology, 73, 19-30. http://dx.doi.org/10.1037/0022-3514.73.1.19

Donchin, E., \& Coles, M. G. H. (1988). Is the P300 Component a Manifestation of Context Updating? Behavioral and Brain Sciences, 11, 357-374. http://dx.doi.org/10.1017/S0140525X00058027

Dweck, C. S. (2006). Mindset: The New Psychology of Success. New York: Random House Publishing Group.

Dweck, C. S. (2009). Who Will the 21st-Century Learners Be? Knowledge Quest, 38, 8-9.

Dweck, C. S. (2012). Mindsets and Human Nature: Promoting Change in the Middle East, the Schoolyard, the Racial Divide, and Willpower. American Psychologist, 67, 614-622. http://dx.doi.org/10.1037/a0029783

Dweck, C. S., Chiu, C., \& Hong, Y. (1995). Implicit Theories and Their Role in Judgements and Reactions: A World from Two Perspectives. Psychological Inquiry, 6, 267-285. http://dx.doi.org/10.1207/s15327965pli0604_1

Endrass, T., Franke, C., \& Kathmann, N. (2005). Error Awareness in a Saccade Countermanding Task. Journal of Psychophysiology, 19, 275-285. http://dx.doi.org/10.1027/0269-8803.19.4.275

Falkenstein, M., Hohnsbein, J., Hoormann, J., \& Blanke, L. (1991). Effects of Crossmodal Divided Attention on Late ERP Components: II. Error Processing in Choice Reaction Tasks. Electroencephalography and Clinical Neurophysiology, 78, 447-455. http://dx.doi.org/10.1016/0013-4694(91)90062-9

Frank, M. J., D’Lauro, C. D., \& Curran, T. (2007). Cross-Task Individual Differences in Error Processing: Neural, Electrophysiological, and Genetic Components. Cognitive, Affective, and Behavioral Neuroscience, 7, 297-308. http://dx.doi.org/10.3758/CABN.7.4.297

Gehring, W. J., Liu, Y., Orr, J. M., \& Carp, J. (2012). The Error-Related Negativity (ERN/Ne). In S. J. Luck, \& E. Kappenman (Eds.), Oxford Handbook of Event-Related Potential Components (pp. 231-291). New York: Oxford University Press.

Good, C., Aronson, J., \& Harder, J. A. (2008). Problems in the Pipeline: Stereotype Threat and Woman’s Achievement in High-Level Math Courses. Journal of Applied Developmental Psychology, 29, 17-28.

Hajcak, G., McDonald, N., \& Simons, R. F. (2003). To Err Is Autonomic: Error-Related Brain Potentials, ANS Activity, and Post-Error Compensatory Behavior. Psychophysiology, 40, 895-903. http://dx.doi.org/10.1111/1469-8986.00107

Herrmann, M. J., Rerrman, J., Ehlis, A., Heidrich, A., \& Fallgatter, A. J. (2004). Source Localization (LORETA) of the Error-Related-Negativity (ERN/Ne) and Positivity (Pe). Cognitive Brain Research, 20, 294-299. http://dx.doi.org/10.1016/j.cogbrainres.2004.02.013

Hong, Y., Chiu, C., Dweck, C. S., Lin, D., \& Wan, W. (1999). Implicit Theories, Attributions and Coping: A Meaning System Approach. Journal of Personality and Social Psychology, 77, 588-599. http://dx.doi.org/10.1037/0022-3514.77.3.588

Iacoboni, M., Molnar-Szakacs, I., Gallese, V., Buccino, G., Mazziotta, J. C., \& Rizzolatti, G. (2005). Grasping the Intentions of Others with One’s Own Mirror Neuron System. PLoS Biology, 3, e79.

Immordino-Yang, M. H. (2009). Our Bodies, Our Minds, Our Selves: Social Neuroscience and Its Application to Education. In S. Feifer, \& G. Rattan (Eds.), The Neuropsychology of Emotional Disorders (pp. 15-22). Middletown, MD: School 
Neuropsychology Press.

Klein, T. A., Ullsperger, M., \& Danielmeier, C. (2013). Assessing Error Awareness without Relying on Introspective Judgment? Frontiers in Neuroscience, 7, 113. http://dx.doi.org/10.3389/fnins.2013.00113

Kujala, T., \& Näätänen, R. (2010). The Adaptive Brain: A Neurophysiological Perspective. Progress in Neurobiology, 91, 55-67. http://dx.doi.org/10.1016/j.pneurobio.2010.01.006

Laming, D. (1979). Choice Reaction Performance Following an Error. Acta Psychologica, 43, 199-224. http://dx.doi.org/10.1016/0001-6918(79)90026-X

Luck, S. (2005). An Introduction to the Event-Related Potential Technique. Cambridge, MA: MIT Press.

Mangels, J., Butterfiels, B., Lamb, J., Good, C., \& Dweck, C. S. (2006). Why Do Beliefs about Intelligence Influence Learning Success? A Social Cognitive Neuroscience Model. Social Cognitive and Affective Neuroscience, 1, 75-86. http://dx.doi.org/10.1093/scan/nsl013

Moser, J. S., Schroder, H. S., Heeter, C., Moran, T. P., \& Lee, Y. H. (2011). Mind Your Errors: Evidence for a Neural Mechanism Linking Growth Mind Set to Adaptive Post-Error Adjustments. Psychological Science, 22, 1484-1489. http://dx.doi.org/10.1177/0956797611419520

Murphy, P. R., Robertson, I. H., Allen, D., Hester, R., \& O’Connell, R. G. (2012). An Electrophysiological Signal That Precisely Tracks the Emergence of Error Awareness. Frontiers in Human Neuroscience, 6, 65. http://dx.doi.org/10.3389/fnhum.2012.00065

Nieuwenhuis, S., Ridderinkhof, K. R., Blom, J., Band, G. P., \& Kok, A. (2001). Error-Related Brain Potentials Are Differentially Related to Awareness of Response Errors: Evidence from an Antisaccade Task. Psychophysiology, 38, $752-760$. http://dx.doi.org/10.1111/1469-8986.3850752

Overbeek, T. J. M., Nieuwenhuis, S., \& Ridderinkhof, K. R. (2005). Dissociable Components of Error Processing: On the Functional Significance of the Pe Vis-à-Vis the ERN/Ne. Journal of Psychophysiology, 19, 319-329. http://dx.doi.org/10.1027/0269-8803.19.4.319

Paunesku, D. (2013). Scaled-Up Social Psychology: Intervening Wisely and Broadly in Education. Ph.D. Thesis, Stanford, CA: Stanford University. https://web.stanford.edu/ paunesku/paunesku_2013.pdf

Rabbitt, P. M. A. (1966). Errors and Error Correction in Choice-Response Tasks. Journal of Experimental Psychology, 71, 264-272. http://dx.doi.org/10.1037/h0022853

Rattan, A., Good, C., \& Dweck, C. S. (2012). “It’s Ok-Not Everyone Can Be Good at Math”: Instructors with Entity Theory Comfort (and Demotivate) Students. Journal of Experimental Social Psychology, 48, 731-737. http://dx.doi.org/10.1016/j.jesp.2011.12.012

Ridderinkhof, K. R. (2002). Micro- and Macro-Adjustments of Task Set: Activation and Suppression in Conflict Tasks. Psychological Research, 66, 312-333. http://dx.doi.org/10.1007/s00426-002-0104-7

Ridderinkhof, K. R., Ramautar, J. R., \& Wijnen, J. G. (2009). To $P_{E}$ or Not to $P_{E}$ : A P3-Like ERP Component Reflecting the Processing of Response Errors. Psychophysiology, 46, 531-538. http://dx.doi.org/10.1111/j.1469-8986.2009.00790.x

Robins, L. R. W., \& Pals, J. (2002). Implicit Self-Theories in the Academic Domain: Implications for Goal Orientation, Attributions, Affect, and Self-Esteem Change. Self and Identity, 1, 313-336. http://dx.doi.org/10.1080/15298860290106805

Schroder, H. S., Moran, T. P., Donnellan, M. B., \& Moser, J. S. (2014). Mindset Induction Effects on Cognitive Control: A Neurobehavioral Investigation. Biological Psychology, 103, 27-37. http://dx.doi.org/10.1016/j.biopsycho.2014.08.004

Steinhauser, M., \& Yeung, N. (2010). Decision Processes in Human Performance Monitoring. The Journal of Neuroscience, 30, 15643-15653. http://dx.doi.org/10.1523/JNEUROSCI.1899-10.2010

Tirri, K., \& Nokelainen, P. (2010). The Influence of Self-Perception of Abilities and Attribution Styles on Academic Choices: Implications for Gifted Education. Roeper Review, 33, 26-32. http://dx.doi.org/10.1080/02783193.2011.530204

van Atteveldt, N., Fernandez, I., de Vries Lentsch, C., \& Krabbendam, L. (2015). The Relevance of Mindsets for Education: Mindset Influences Post-Error Adjustments on a Math Task. Paper Presented at the 16th Biennial Conference of the European Association for Research in Learning and Instruction (EARLI), Limassol, Cyprus. http://www.earli2015.org/media/EARLI2015/docs/EARLI2015 bookOfAbstracts.pdf

Yeager, D. S., \& Dweck, C. S. (2012). Mindsets that Promote Resilience: When Students Believe That Personal Characteristics Can Be Developed. Educational Psychologist, 47, 302-314. http://dx.doi.org/10.1080/00461520.2012.722805

Yeager, D. S., \& Walton, G. M. (2011). Social-Psychological Interventions in Education: They're Not Magic. Review of Educational Research, 81, 267-301. http://dx.doi.org/10.3102/0034654311405999

Yeager, D., Trzesniewski, K. H., \& Dweck, C. S. (2012). An Implicit Theory of Personality Intervention Reduces Adolescent Aggression in Response to Victimization and Exclusion. Child Development, 84, 970-988.

http://dx.doi.org/10.1111/cdev.12003 
Yeager, D., Trzesniewski, K. H., Tirri, K., Nokelainen, P., \& Dweck, C. S. (2011). Adolescents’ Implicit Theories Predict Desire for Vengeance after Remembered and Hypothetical Peer Conflicts. Developmental Psychology, 47, 1090-1107. http://dx.doi.org/10.1037/a0023769

\section{Submit or recommend next manuscript to SCIRP and we will provide best service for you:}

Accepting pre-submission inquiries through Email, Facebook, LinkedIn, Twitter, etc.

A wide selection of journals (inclusive of 9 subjects, more than 200 journals)

Providing 24-hour high-quality service

User-friendly online submission system

Fair and swift peer-review system

Efficient typesetting and proofreading procedure

Display of the result of downloads and visits, as well as the number of cited articles

Maximum dissemination of your research work

Submit your manuscript at: http://papersubmission.scirp.org/ 